\title{
eCOti
DiAno
}

Revista Mídia e Cotidiano

Artigo Seção Temática

Volume 13, Número 3, dezembro de 2019

Submetido em: 30/09/2019

Aprovado em: 08/11/2019

\section{Saberes necessários da educação midiática na era da desinformação}

\section{Necessary knowledge of media education in the age of disinformation}

\author{
Egle Müller SPINELLI ${ }^{1}$ \\ Jéssica de Almeida SANTOS ${ }^{2}$
}

\section{Resumo}

Este artigo propõe reflexões sobre a implementação do campo jornalístico-midiático da Base Nacional Curricular Comum (BNCC) diante do grave cenário de desinformação que assola o Brasil. A pesquisa bibliográfica parte do pressuposto de que a formação em educação midiática proporciona conhecimentos, habilidades, atitudes e competências fundamentais para o século XXI e os saberes necessários para a educação do futuro. (BUCKINGHAM, 2019; MORIN, 2000; FREIRE, 2014). Com base nos trabalhos realizados em Portugal, que definiu como estratégia análise de cenário, diagnóstico e construção de um referencial específico para educação midiática, sugerimos que o tema merece discussões mais aprofundadas e o envolvimento de diversos atores no Brasil, em um esforço orquestrado para formar um cidadão ativo, crítico e preparado para lidar com a avalanche de informações da nossa era.

Palavras-chave: Desinformação; Educação Midiática; BNCC; Campo JornalísticoMidiático.

\begin{abstract}
This article reflects about the implementation of the journalistic-media field of the Common National Curriculum Base (CNCB) in the face of the serious scenario of disinformation that hits Brazil. The bibliographic research assumes that media education provides fundamental knowledge, skills, attitudes and competencies for the 21st century and the knowledge needed for future education (BUCKINGHAM, 2019; MORIN, 2000; FREIRE, 2014). Based on the work done in Portugal, which defined as strategy the scenario analysis, diagnosis and construction of a specific reference for media education, we suggest that the theme deserves further discussions and the involvement of several

\footnotetext{
${ }^{1}$ Docente do curso de Jornalismo e do Programa de Pós-Graduação em Comunicação e Práticas de Consumo da ESPM (PPGCOM, ESPM-SP), doutora em Ciências da Comunicação pela Universidade de São Paulo. E-mail: egle.spinelli@espm.br Universidade Presbiteriana Mackenzie e graduação em Comunicação Social - Jornalismo, pelas Faculdades Integradas Rio Branco. E-mail: almeidasts.jessica@gmail.com
}

${ }^{2}$ Mestre em Jornalismo pela ESPM. Possui Pós-Graduação em Marketing e Comunicação Integrada, pela
\end{abstract}




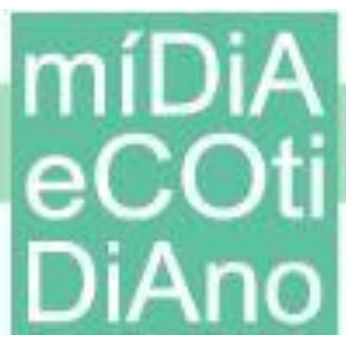

players in Brazil, in an orchestrated effort to form an active, critical and prepared citizen to deal with the flood of information of our age.

Keywords: Disinformation; Media Literacy; CNBC; Journalist-Media Field.

\section{Introdução}

Em apenas 60 segundos, o mundo hiperconectado troca mais de 41 milhões de mensagens no WhatsApp e no Messenger, assiste 4,5 milhões de vídeos no Youtube e publica 87.500 tweets (DESJARDINS, 2019).Quem ocupa o ciberespaço no século XXI reconfigura e remixa conteúdos de mídia de forma inédita, e a mudança cultural posta pelas novas tecnologias fortalece um movimento em que web-atores quebram o monopólio da produção e da disseminação de conteúdos. $\mathrm{O}$ advento da democratização da comunicação estratifica um banco de informações global infinito, mas muitas vezes sem nexo, autoria, veracidade ou relevância. Os filtros do mundo linear não funcionam na era digital, regida por multiplicidade, velocidade, efemeridade, descentralização, abundância e complexidade. O caos informacional do século XXI vai, aos poucos, provocando o definhamento do ser crítico. É este cidadão confuso, com o poder de disseminar informação em poucos segundos, que carrega nas costas o peso de tomar decisões importantes em um sistema democrático (RAMONET, 2012; HAN, 2013). Como podemos exercer nossa cidadania de forma plena e responsável com um celular conectado nas mãos? Enquanto "os principais estruturantes da informação do mundo analógico colapsaram com as plataformas digitais, transferindo poder, e, ao mesmo tempo, responsabilidade informacional aos indivíduos”, é urgente que políticas públicas sejam implementadas para equilibrar o cenário informativo (MARTHA GABRIEL, 2018, p. 10-11).

Contextualizar esta era na esfera midiática exige olhares multidisciplinares, como o estudo The spread oftrueand false news online, em que pesquisadores do Instituto Tecnológico de Massachusetts (MIT) descobriram que conteúdos falsos são disseminados mais rapidamente e têm um alcance $70 \%$ maior do que os verdadeiros, independentemente do tema (VOSOUGHI, DEB, ARAL, 2018). E ao apontar o cidadão comum - e não bots - como o grande disseminador desse tipo de conteúdo, é reforçado o papel centralizador das redes sociais que permite aos leitores escolherem a história, e não 


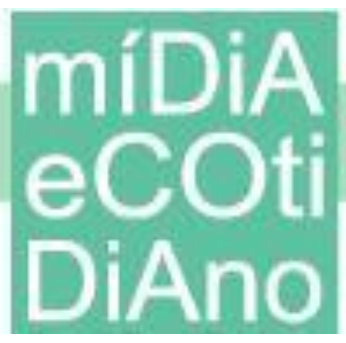

necessariamente quem vai contá-la. Essa mudança representa uma ruptura no processo tradicional de gatekeeping do jornalismo ${ }^{3}$, associada à gama de fontes consideradas e à recomendação dos amigos (MESSING; WESTWOOD, 2012).

Não que pautar decisões por meio de mentiras - e não por fatos - seja novidade. A humanidade sempre viveu em uma pós-verdade e o poder de dominação do homo sapiens frente às outras espécies está intimamente relacionado à habilidade de criar ficções e acreditar nelas. Na terra da era digital com informações e escolhas infinitas, as pessoas criam seu ambiente de mídia pessoal em busca de conteúdos - textos, áudios, vídeos - que confirmemse o que sentem e defendem é verdadeiro. A exposição seletiva de ideias pautada por algoritmos-curadores contribui para a polarização extrema e condena os indivíduos a viveram em um mundo construído a partir dos próprios fatos (HARARI, 2018; MANJOO, 2008; TUFEKCI, 2015).

Em um esforço para entender o que está acontecendo, Wardle e Derakhshan (2017) sugerem que a sociedade enfrenta um fenômeno que combina três categorias em um contexto amplo de desordem informacional: a desinformação (disinformation), notícias falsas criadas deliberadamente e disseminadas para prejudicar uma pessoa, um grupo social, uma organização ou um país; a informação falsa (misinformation), mas que não tem a intenção de causar dano; e a má-informação (mal-information), que possui bases reais que são editadas e divulgadas com a finalidade de causar danos.

O fenômeno passou a chamar atenção do mundo após Donald Trump assumir a presidência dos Estados Unidos com uma avalanche de conteúdos fabricados, além da perigososa associação do termo fakenews à divulgação de fatos que discordassem ou incriminassem atitudes do republicano (AHRENS, 2017; IANDOLI, 2017). Desde 2016, os olhares estão voltados para o impacto da desinformação em processos democráticos e no agravamento da polarização entre os que pensam diferente. Um estudo encomendado pelo Serviço Mundial da BBC, indicou uma divulgação amplificada e coesa de mensagens falsas por grupos de direita na Índia, Quênia e Nigéria (BBC, 2018). No

${ }^{3}$ A teoria do gatekeeper avalia o processo de seleção da notícia, além de como o conteúdo é modelado, estruturado, posicionado e cronometrado (SHOEMAKER, 2011). Segundo o autor, o fluxo de notícias passa por diversos gates (portões) até a sua publicação e, para isso, os jornalistas a partir de critérios subjetivos, pessoais e até institucionais, determinam qual notícia será, ou não, repassada ao público. 


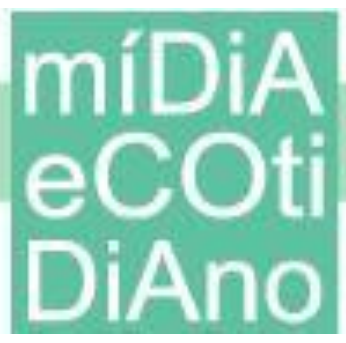

Brasil, a pedido da Universidade de São Paulo (USP) e da Universidade Federal de Minas Gerais (UFMG), os fact-checkers da Agência Lupa analisaram o grau de veracidade de 50 imagens que circularam no WhatsApp entre os dias 16 de agosto e 7 de outubro de 2018, durante o primeiro turno eleitoral. Desse conjunto, apenas quatro eram comprovadamente verdadeiras (FOLHA DE S. PAULO, 2018; TARDÁGLIA; BENEVENUTO; ORTELLADO, 2018). Reportagem da BBC participou durante uma semana de grupos públicos do Whatsapp com apelo político, em que links, áudios, fotos e vídeos eram compartilhados sem critérios ou checagens. A experiência mostrou que milhões de pessoas estavam expostas à desinformação, ataques à imprensa tradicional, com capas de revistas falsas, imagens fomentando ódio às minorias, guerra cultural com ataques sistematizados a artistas, que impactaram significadamente os debates, as relações e quem sabe até mesmo o resultado das eleições de 2018 (GRAGNANI, 2018).

De acordo com o relatório do Oxford Internet Institute, a propaganda computacional - o uso de algoritmos, automação e big data para moldar a vida pública, tornou-se uma ferramenta de controle da informação em governos autoritários de três formas: suprimindo direitos humanos fundamentais, desacreditando oponentes políticos e abafando opiniões divergentes. Em 2019, foram identificadas ações de manipulação em 70 países, índice que cresceu $150 \%$ desde 2017 , e os autores do estudo alertam para o uso orquestrado das redes sociais na amplificação da desinformação, na incitação à violência e na crescente desconfiança da sociedade nas instituições, como governo e imprensa (BRADSHAW, HOWARD, 2019).

O cenário informativo se torna cada vez mais complexo e perigoso, e se realmente queremos que os cidadãos saibam o que fazer para lidar com o ambiente digital povoado por cruzadas manipuladoras financiadas pelo próprio Estado, precisamos exigir investimentos em programas abrangentes e sistemáticos de educação midiática como base de direito a todos os jovens (BUCKINGHAM, 2019). Obviamente que a educação midiática não deve ser alçada como solução, pois para funcionar deve estar sustentada por um programa educacional abrangente, visto que nações que historicamente investem em educação sofrem menos com o impacto da desinformação. A Finlância, por exemplo, em 2014 já ensinava em sala de aula sobre os riscos da deepfakee as ameaças da Rússia e seu exército de trolls, em uma das iniciativas que fazem parte da abordagem 


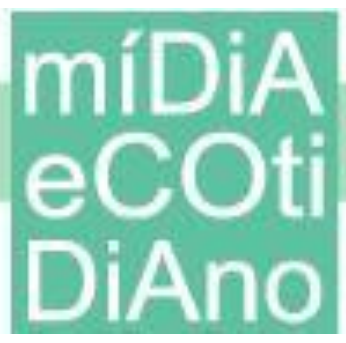

multisetorial e intersetorial para preparar cidadãos de todas as idades para o cenário digital. O esforço levou a Finlância à primeira posição no Media Literacy Index, criado em 2017 para avaliar o potencial de 35 países europeus para lidar com a desinformação, empregando indicadores de liberdade de mídia, educação, confiança e participação cívica. Como regra, os últimos lugares estão relacionados ao baixo desempenho educacional e à dificuldade em garantir a liberdade de imprensa (LESSENSKI, 2018; MACKINHTOSH, 2019).

Diante do desafio em desenvolver competências que permitam às crianças uma atitude crítica e exigente com a mídia, é fundamental que diversos atores - governo, representantes da sociedade, escolas, veículos de mídia, universidades - se unam para estabelecer políticas públicas que reconheçam na educação midiática suas vertentes interdisciplinares.

Para efeitos de conceituação, considera-se o que Pinto et al (2011) definem como educação midiática, pela amplitude em classificar a área como algo integrador, o que veremos adiante que dialoga com os pensamentos de Freire (2013), Morin (2000) e Buchingham (2019):

[...] o conjunto de conhecimentos, capacidades e competências (e os processos da respectiva aquisição) relativas ao acesso, uso esclarecido, pesquisa e análise crítica da mídia, bem como as capacidades de expressão e de comunicação através desses mesmos media (PINTO et al, 2011, p. 24, grifo nosso).

Com a implementação da Base Nacional Curricular Comum (BNCC) e a criação do campo jornalístico-midiático em Língua Portuguesa como um espaço no currículo que pode "funcionar" como educação midiática, questiona-se, neste artigo, por meio de uma pesquisa bibliográfica com abordagem qualitativa, dois pontos principais: 1) natureza interdisciplinar da educação midiática na proposta da BNCC e 2) amadurecimento das discussões sobre educação midiática no Brasil, tendo em vista o modelo de trabalho desenvolvido em Portugal. As duas questões provocam uma discussão embrionária sobre como a educação midiática será implementada no Brasil e os desafios que enfrentaremos para garantir que estas competências sejam desenvolvidas em nossos estudantes. 


\section{A essência complexa da educação midiática}

Não pertencer ao seu tempo e se sentir exilado é a pior lástima que pode ocorrer a um ser humano. A afirmação de Paulo Freire é indispensável para reforçar que o pertencimento ao tempo do século XXI requer entendimento de que a mídia é uma dimensão central da vida contemporânea - da cultura, da política, da economia e das relações pessoais, e abster o cidadão do conhecimento sobre as ferramentas para compreender esse processo é contribuir para isolá-lo à classe dos inúteis (FREIRE, GUIMARÃES, 2013; BUCKINGHAM, 2019). Freire impele as escolas a estarem à altura das novas exigências sociais e históricas e a não temerem o diálogo com os meios de comunicação. A educação transformadora deve provocar e propagar a abertura, e não a oclusão mental (BAUMAN, 2013).

A definição de educação midiática como um conjunto de capacidades, conhecimentos e competências para acesso, uso, pesquisa e análise crítica de mídia está atrelada, neste artigo, à sistemização de Morin (2000) sobre os saberes necessários para a educação do século XXI. O recorte aqui sugerido destaca a quebra de paradigma que sugere a descompartimentalização do conhecimento, buscando uma integração das disciplinas. Abordar a educação midiática em e além da sala de aula nada mais é do que “armar cada um para o combate vital para a lucidez" (MORIN, 2000, p. 33). Como visto anteriormente, a desinformação é apenas um dos sintomas de uma grave crise de confiança em instituições, como o governo, a imprensa, a ciência e a até nas próprias pessoas. Ao promover um conhecimento capaz de apreender problemas globais e fundamentais para neles inserir os conhecimentos parciais e locais, a educação midiática vai além de uma visão simplista e limitadora de benefícios e riscos, e serve como ferramenta que permite ao cidadão comunicar-se de forma autônoma, responsável e crítica. No final das contas, o entendimento crítico também precisa levar à ação: o objetivo não é apenas interpretar o mundo, mas também mudá-lo (BUCKINGHAM, 2019).

Morin (2011, p. 7) defende ainda que a atribuição de sentido ao mundo complexo pede um pensamento complexo, em uma permanente tensão entre "a aspiração a um saber não fragmentado, não compartimentado, não redutor, e o reconhecimento do 
inacabado e da incompletude de qualquer conhecimento". Ao mesmo tempo, refletir sobre uma proposta de educação midiática que efetivamente cumpra com seus propósitos é um "lugar crucial de interrogações" (MORIN, 2011, p. 8).

Partindo do pensamento complexo de Morin (2011) e das exortações de Buckingham (2019) e Freire (2014) sobre uma educação transformadora para a mídia, cabem reflexões sobre os riscos de uma possível fragmentação do aprendizado da educação midiática se esta ficar restrita ao campo jornalístico-midiático da Base Nacional Curricular Comum. Aprovada pelo Ministério da Educação em 2017, a BNCC é um avanço na educação brasileira por definir o conjunto de aprendizagens essenciais que todos os alunos devem desenvolver ao longo das etapas e modalidades da Educação Básica das redes escolares dos Estados, do Distrito Federal e dos Municípios. O documento normativo deve ser considerado na construção de propostas pedagógicas, materiais didáticos e processos de avaliação de aprendizagem para a sala de aula. A base é um ponto de partida para contribuir com o alinhamento de outras políticas e ações referentes “à formação de professores, à avaliação, à elaboração de conteúdos educacionais e aos critérios para a oferta de infraestrutura adequada para o pleno desenvolvimento da educação" (MEC, 2018).

Dentro da BNCC, a prática de linguagem definida como Campo Jornalístico/Midiático, dentro da área de conhecimento de Língua Portuguesa, é a que mais se aproxima de uma abordagem de educação midiática, com os objetivos de:

1. ampliar e qualificar a participação das crianças, adolescentes e jovens nas práticas relativas ao trato com a informação e opinião, que estão no centro da esfera jornalística/midiática.

2. para além de construir conhecimentos e desenvolver habilidades envolvidas na escuta, leitura e produção de textos que circulam no campo, o que se pretende é propiciar experiências que permitam desenvolver nos adolescentes e jovens a sensibilidade para que se interessem pelos fatos que acontecem na sua comunidade, na sua cidade e no mundo e afetam as vidas das pessoas

3. incorporem em suas vidas a prática de escuta, leitura e produção de textos pertencentes a gêneros da esfera jornalística em diferentes fontes, veículos e mídias,

${ }^{4} \mathrm{O}$ conceito de pensamento complexo é defendido por Edgar Morin como uma aspiração ao conhecimento multidimensional, que dê conta "das articulações entre os campos disciplinares que são desmembrados pelo pensamento disjuntivo" (MORIN, 2011, p. 6). 
4. desenvolvam autonomia e pensamento crítico para se situar em relação a interesses e posicionamentos diversos e possam produzir textos noticiosos e opinativos e participar de discussões e debates de forma ética e respeitosa (MINISTERIO DA EDUCAÇÃO, 2017, p. 138, grifo nosso).

O campo jornalístico-midiático se concentra nos Anos Finais do Ensino Fundamental ( $6^{\circ}$ ao $9^{\circ}$ ano) e no Ensino Médio ( $1^{\mathrm{a}}$ a $3^{\mathrm{a}}$ série), abrangendo alunos de 12 a 17 anos. Divide espaço em Língua Portuguesa com outros cinco campos: artísticoliterário, vida cotidiana, vida pública, prática de estudos e pesquisa, atuação na vida. $\mathrm{O}$ documento que direciona as escolas na construção do currículo reúne ainda a prática de linguagem (análise linguística/semiótica; leitura; oralidade e produção de textos) que se relaciona com o objeto de conhecimento e as habilidades trabalhadas. A seguir, um exemplo de como a BNCC indica a construção do trabalho relacionado à temática de liberdade de expressão e discursos de ódio:

Tabela 1 - Construção do trabalho relacionado à temática de

liberdade de expressão e discursos de ódio

\begin{tabular}{|l|l|l|l|}
\hline Ano/faixa & $\begin{array}{l}\text { Prática de } \\
\text { linguagem }\end{array}$ & \multicolumn{1}{|c|}{$\begin{array}{c}\text { Objetos de } \\
\text { conhecimento }\end{array}$} & \multicolumn{1}{|c|}{ Habilidades } \\
\hline & Leitura & $\begin{array}{l}\text { Apreciação e réplica } \\
\text { Relação entre gêneros e } \\
\text { mídias }\end{array}$ & $\begin{array}{l}\text { (EF69LP01) Diferenciar } \\
\text { liberdade de expressão de } \\
\text { discursos de ódio, } \\
\text { posicionando-se } \\
\text { contrariamente a esse tipo de } \\
\text { discurso e vislumbrando } \\
\text { possibilidades de denúncia } \\
\text { quando for o caso. }\end{array}$ \\
\hline
\end{tabular}

Fonte: MEC (2018).

O documento traz ainda um material suplementar para ajudar as escolas na construção do currículo, com comentários dos redatores, que sugerem as possibilidades de trabalho interdisciplinar. No exemplo citado na tabela acima, as possibilidades são:

Na elaboração do currículo, é importante incluir projetos que abordem fatos e assuntos polêmicos específicos do estado e/ou município do aluno, bem como a possibilidade de os estudantes terem participação efetiva nas discussões dessas questões. Considerar as possibilidades de interação dos alunos com jornais e revistas locais, impressos ou digitais, por exemplo, e planejar a sua participação ativa nesses meios 
contribuirá para o desenvolvimento desta habilidade. Também favorece esse desenvolvimento discutir a diferença entre liberdade de expressão e discursos de ódio (que podem ser evidenciados em situações de bullying, por exemplo).Há, aqui, oportunidade de trabalho interdisciplinar com as habilidades (EF69AR15), (EF69AR33), da Arte; e (EF67EF17), da Educação Física, no que se refere à compreensão crítica de diferentes pontos de vista sobre temas controversos e de relevância social (MEC, 2018, grifo nosso).

Primeiramente, é importante ressaltar que o país está atento à necessidade de abordar a educação midiática, campo exigido até mesmo pelo Pisa (Programme for International Student Assessment), que passou a avaliar se os países estão sendo bemsucedidos em ensinar aos jovens a compreenderem o mundo globalizado em que vivem. No documento que orienta as novas competências globais, destaca-se a necessidade de usar plataformas de mídia de forma eficaz e responsável, considerando que "o acesso a uma quantidade ilimitada de informações é muitas vezes associado à falta de alfabetização midiática, o que significa que os jovens são facilmente enganados por notícias partidárias, tendenciosas ou falsas”. Nesse contexto, a OCDE recomenda aos países que "cultivar a competência global dos alunos pode ajudá-los a capitalizar os espaços digitais, entender melhor o mundo em que vivem e expressar com responsabilidade sua voz on-line" (THE OECD, 2018, p. 5). Para o próximo teste, em 2021, estuda-se incluir questões específicas de educação midiática, para avaliar a capacidade dos adolescentes de diferenciar informações e fraudes.

Do ponto de vista do âmbito da construção, o campo foi criado para refletir um fazer do professor em sala de aula que chegasse ao aluno como uma mudança possível na aprendizagem. Ao mesmo tempo, foram respeitados os conhecimentos linguísticos bem estruturados e evitados a simplificação que pode resultar na banalização dos conhecimentos. A maior preocupação sempre foi de que o núcleo - formação do leitor e do produtor de textos - estivesse presente em cada opção, centrado nas relações solidárias entre os diferentes conhecimentos. Assim, um campo não é visto fora da alçada dos outros e, até mesmo, do diálogo com as outras disciplinas. E o que este artigo defende é exatamente o diálogo necessário entre o campo jornalístico-midiático e outras áreas de conhecimento, pois é fundamental que o debate acerca da mídia seja entrelaçado com as ciências humanas, por exemplo. Discussões como o papel da globalização no 


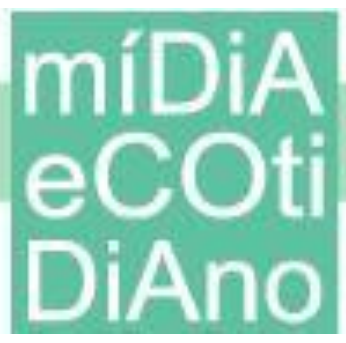

encurtamento dos tempos e espaços e como a mídia se comporta nesse cenário, devem romper barreiras de disciplinas e conversar com outras áreas. Volta-se a Paulo Freire, que relaciona o verdadeiro aprendizado à percepção do "condicionamento históricosociológico do conhecimento e à busca das relações entre o conteúdo em estudo e outras dimensões afins do conhecimento" (FREIRE, 1978, p. 10). Obviamente não é somente a educação midiática que pede esta troca, e sabe-se que o diálogo entre as áreas de conhecimento é fundamental no processo de ensino-aprendizagem e estimulado pela própria BNCC. Mas diante das dificuldades que o país sempre enfrentou para executar uma política pública coerente para a educação, é natural antever que as escolas terão dificuldades em colocar em prática a educação midiática.

É reconhecido que o país reúne diversas iniciativas que alcançaram êxito em trabalhar os pilares de educação midiática. Caprino e Martinez-Cerdá (2015) catalogaram 129 ONGs e instituições civis que realizam 302 projetos de educação midiática no Brasil, categorizados conforme abaixo:

- Dimensões: acesso / uso, compreensão crítica, e produção de conteúdo.

- Atores: receptores, profissionais, associados e patrocinadores.

- Mídia de comunicação: impressão (jornais, revistas, boletins informativos e outros); audiovisual (cinema, vídeo, TV, rádio / áudio, fotografia e outros); TIC (Internet, web design, aplicativos e outros); digital mídia (sites, blogs, redes sociais, mídias móveis, e outros); monitoramento e acompanhamento da comunicação mídia (monitoramento de temas relacionados às ONGs, produção de diretrizes e notícias alternativas, treinamento de jornalistas e outros).

- Tecnologias digitais: nível de importância do TIC e ênfase na inclusão digital.

- Comunicação Comunitária: como permanente veículo e atores envolvidos.

- Empoderamento: explicitamente conectado à mídia-educação, defesa dos direitos e papel dos cidadãos (CAPRINO, MARTINEZCERDÁ, 2016, p. 41).

Vale ressaltar que 70 projetos estão ligados a conteúdos críticos de compreensão e produção, dentre os quais 22 também se concentram no acesso e uso dos meios de comunicação. Os pesquisadores enfatizam que a simples produção de conteúdo nem sempre resulta em empoderamento para os cidadãos, pois é possível que uma 


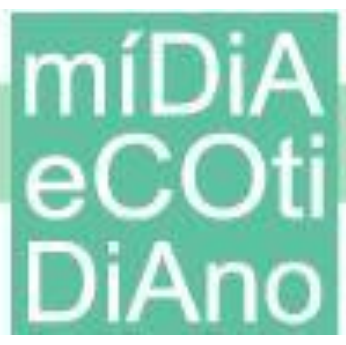

atividade simplesmente reproduza algo que já existe na mídia. O desenvolvimento de habilidades comunicacionais está intimamente relacionado à compreensão crítica. Portanto, cobra-se, aqui, diagnóstico e sistematização. Por isso, o segundo questionamento deste artigo busca apontamentos no trabalho realizado por Portugal para entender que o processo de construção de um referencial interdisciplinar próprio de educação midiática parte, inicialmente, de um diagnóstico: o que temos, como fazemos e para aonde queremos ir.

\section{O referencial de educação midiática português}

Em 2011, pesquisadores da Universidade do Minho realizaram um amplo estudo encomendado pela Entidade Reguladora para a Comunicação (ERC) para mapear o status da educação midiática em Portugal. O estudo concluiu que, no recorte proposto de dez anos, havia projetos interessantes e diversificados, realizados por associações, veículos de mídia, escolas e entidades oficiais. No entanto, o panorama geral sobre a educação midiática se mostrava fragmentado, e com poucas chances de avanços por esta natureza desorganizada. Os pesquisadores entenderam, à época, que uma educação neste nível "não tem sido uma prioridade para as entidades governamentais, independentemente da orientação político-partidária" (PINTO et al, 2011, p. 149). A temática acabava sendo discutida na disciplina de educação para a cidadania, obrigatória para toda a educação básica, mas ainda apresentava muitas dificuldades em firmar-se como ação pedagógica, cultural e política.

Diante do diagnóstico, o estudo recomendou que mais esforços e investimentos em pesquisa sobre o tema fossem feitos. Outra sugestão foi de que as universidades deveriam incluir a educação midiática no currículo de formação docente, tanto na graduação quanto na pós-graduação, para que os professores saíssem da faculdade aptos a desenvolver estas competências nos estudantes. Por último, o estudo incentivava a exploração do potencial da educação midiática além dos muros da escola, em que as famílias e instituições pudessem também discutir o tema; posicionamento das organizações de mídia e envolvimento do Estado em criar metas e objetivos na implementação da educação midiática, assim como a avaliação dos resultados obtidos, em uma sistematização do que já existia para potencializar as experiências. 
O trabalho desenvolvido em Portugal foi pautado pelas orientações dispostas na diretiva 2007/65/EC do Parlamento Europeu e do Conselho, de 11 de dezembro de 2007, que exigia das nações europeias ações efetivas de educação midiática.

[...] A Educação Midiática deverá por conseguinte ser fomentada em todos os setores da sociedade e os seus progressos deverão ser acompanhados de perto. A Recomendação do Parlamento Europeu e do Conselho, de 20 de Dezembro de 2006, relativa à proteção dos menores e da dignidade humana e ao direito de resposta em relação à competitividade da indústria europeia de serviços audiovisuais e de informação em linha [20], contém já uma série de medidas suscetíveis de fomentar educação midiática, tais como, por exemplo, a formação contínua de professores e formadores, a aprendizagem específica da Internet destinada às crianças desde a mais tenra idade, incluindo sessões abertas aos pais, ou a organização de campanhas nacionais junto dos cidadãos, envolvendo todos os meios de comunicação social, de modo a divulgar informações sobre a utilização responsável da internet (PINTO et al, 2011, p. 199, grifo nosso).

O documento determinava que os países apresentassem relatórios comprobatórios da aplicação da diretiva até 2011, e que, a partir daí, a prestação de contas sobre o trabalho de educação midiática passasse a ser trienal. No caso português, após o trabalho inicial de diagnóstico, em 2014 foi publicado o Referencial de Educação para os Media, também produzido pela Universidade do Minho, com objetivo de propor um quadro de referência para o trabalho pedagógico em torno das questões da educação midiática na educação básica, tomando como referência documentos de diversos países, bem como as posições recentes de instituições europeias e internacionais.

[o documento] considera que a educação midiática possui uma dimensão transversal da Educação para a Cidadania, em contexto de ensino e de aprendizagem de qualquer disciplina ou área disciplinar, nos $1 .^{\circ}, 2 .^{\circ}$ e $3 .^{\circ}$ ciclos do ensino básico e no ensino secundário e também no quadro da educação pré-escolar, tendo em conta a Orientações Curriculares para a Educação Pré-Escolar em vigor; Propõe-se, assim, o tratamento progressivo, desde a educação préescolar até aos ensinos básico e secundário, de diversos temas: 1. Comunicar e informar; 2. Compreender o mundo atual; 3. Tipos de Media; 4. As TIC e os ecrãs; 5 . As redes digitais; 6 . Entretenimento e espetáculo; 7. Publicidade e marcas; 8. Produção e indústria/ profissionais e empresas; 9. Os Media como construção social; 10. Audiências, públicos e consumos; 11. Liberdade e ética, direitos e 
deveres; 12. Nós e os Media. Cada um destes temas engloba subtemas e objetivos (PEREIRA et al, 2014, p. 8).

Com o referencial, o processo pedagógico necessário para a promoção de educação midiática fica muito claro, objetivo e prático. O documento prevê dez grandes princípios, e estrutura o conteúdo em temas, subtemas, objetivos gerais e objetivos específicos. Utilizando o mesmo recorte do campo jornalístico-midiático citado na página 7, sobre liberdade de expressão e discursos de ódio, percebe que o referencial português encaixa a temática em um contexto amplo de Liberdade e ética, direitos e deveres, conforme quadro abaixo:

Tabela 2 - Temática Liberdade e ética, direitos e deveres

\begin{tabular}{|c|c|c|c|}
\hline Temas & Subtemas & Objetivos gerais & Objetivos específicos \\
\hline $\begin{array}{l}\text { 10. Liberdade } \\
\text { e ética, } \\
\text { direitos e } \\
\text { deveres }\end{array}$ & $\begin{array}{l}\text { - Liberdade de } \\
\text { Informação e } \\
\text { de expressão } \\
\text { - Direitos e } \\
\text { Deveres }\end{array}$ & $\begin{array}{l}\text { Compreender o } \\
\text { direito à } \\
\text { liberdade de } \\
\text { informação e de } \\
\text { expressão. }\end{array}$ & $\begin{array}{l}\text { - Saber porque é importante informar, informar- } \\
\text { se e ser informado livremente } \\
\text { - Conhecer os principais documentos que } \\
\text { consagram o direito à liberdade de informação e } \\
\text { de expressão } \\
\text { - Reconhecer a liberdade de expressão como } \\
\text { um direito humano fundamental (art.o } 19 .^{\circ} \text { da } \\
\text { Declaração Universal dos Direitos Humanos) } \\
\text { - Conhecer a censura, a sua história e as suas } \\
\text { características } \\
\text { - Compreender o que é o interesse público da } \\
\text { informação e entender porque o interesse público } \\
\text { não é o mesmo que o interesse do público } \\
\text { - Perceber porque é relevante distinguir vida } \\
\text { pública e vida privada e porque importa respeitar } \\
\text { o direito à privacidade } \\
\text { - Conhecer os direitos de autor e entender porque } \\
\text { devem ser respeitados } \\
\text { - Conhecer o trabalho dos provedores do leitor, } \\
\text { do ouvinte e do telespectador, percebendo a } \\
\text { função que desempenham e a eles recorrendo, } \\
\text { sempre que for pertinente }\end{array}$ \\
\hline
\end{tabular}

Fonte: PEREIRA et al, 2014, p. 14.

Ao integrar os saberes ligados à educação midiática, o aprendizado naturalmente segue uma linha uniforme, facilitando até mesmo o processo de avaliação dos resultados, que é um dos pontos de melhoria nos esforços de aplicação da educação midiática. Afinal, o estudante que recebe esta educação, desde a pré-escola, realmente se 


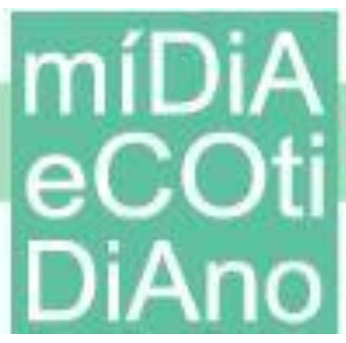

torna capaz de compreender e avaliar de modo crítico os diferentes aspectos dos media e dos seus conteúdos e de criar comunicações em diversos contextos?

Mas antes disso, existe a grande dificuldade em fazer acontecer nas escolas. Portugal ainda encontra muitos desafios em convencer as escolas a adotar o referencial, e foram realizados cursos para formação de formadores, com objetivo de prepará-los para multiplicar o conhecimento de educação midiática e aplicar o referencial em suas escolas. Recentemente, o governo português adotou um novo projeto para alavancar a educação midiática, o Competências de Literacia Digital e Midiática COMEDIG 2020. A parceria com as universidades de Coimbra e do Minho pretende diagnosticar o nível de competências de educação midiática de alunos e professores da educação básica ao ensino superior, e com base no conhecimento produzido, desenhar recursos educativos e orientações para a intervenção na área da educação mediática (UNIVERSIDADE DE COIMBRA, 2019).

\section{Considerações Finais}

A desinformação deve ganhar ainda mais força nos próximos anos, considerando o avanço da tecnologia, a polarização extrema entre grupos que pensam diferente e utilizam redes sociais para disseminar ódio com mensagens enganosas, e a falta de políticas públicas para a questão. O tema é complexo, e o que se vê é uma busca frenética por soluções que se adequem à cultura e às necessidades de cada país, mas ainda poucas ações concretas.

Programas de educação midiática para todos os níveis educacionais são fundamentais para construirmos uma estratégica efetiva de formação de estudantes críticos e aptos para lidar com a mídia. As crianças e jovens se mostram mais frágeis para enfrentar este contexto informativo tóxico. Apenas $2 \%$ das crianças e dos adolescentes do Reino Unido têm a capacidade de leitura crítica necessária para discernir uma notícia falsa de uma notícia verdadeira, de acordo com um relatório publicado em junho deste ano pelo Conselho Nacional de Alfabetização do Reino Unido (NATIONAL LITERACY TRUST, s/d). Além disso, a proliferação de notícias falsas causa ansiedade nos alunos e prejudica a autoestima e a visão que os estudantes têm sobre o mundo. 
Entendemos que a inclusão do campo jornalístico-midiático na Base Nacional Curricular Comum - BNCC é um passo importante para incluir a educação midiática nos currículos das escolas básicas do país. A preocupação com a garantia de que as habilidades sejam trabalhadas de forma interdisciplinar é válida, de forma que o campo não fique restrito aos gêneros textuais. Trabalhar os saberes da educação midiática é desafiador, e a construção do currículo tem na formação do professor um pilar fundamental para que possa acontecer de verdade. $\mathrm{O}$ caso português vem à tona e serve de inspiração por focar a estratégia em diagnósticos, propostas de referencial e, diante das dificuldades em emplacar a educação midiática, propor novos estudos com as universidades parceiras para ampliar as percepções e produzir novos materiais de apoio.

Como este artigo tentou mostrar, é possível abrir um espaço de diálogo entre educadores, jornalistas, governo, grupos de mídia e universidades, para que exista a transformação da escola em um espaço de discussão do tema, e se proporcione aos alunos a base necessária para que eles cresçam preparados para combater o ambiente de desinformação. Mas o caminho para esta construção passa por reflexões e criação de pontes entre esses atores.

\section{Referências}

AHRENS, Jan Martínez. Trump e as 'fakenews' atacam de novo. El Pais. Washington, 08 maio 2017. Disponível em: 〈https://goo.gl/Jqdx3B> Acesso em: 24 jul. 2017.

BAUMAN, Zygmunt. Sobre educação e juventude: conversas com Ricardo Mazzeo. São Paulo: Zahar, 2013. Edição Kindle.

BBC. Onda de nacionalismo está por trás de fakenews na Índia, mostra pesquisa inédita da BBC. 12 nov. 2018. Disponível em: <https://bbc.in/37PFf2d>. Acesso em: 14 dez. 2018.

BRADSHAW, Samantha; HOWARD, Philip N. The Global Disinformation Order: 2019 global inventory of organised social media manipulation. Oxford Internet Institute. Disponível em: <https://bit.ly/2q4Sz1J>. Acesso em: 28 set. 2019

BUCKINGHAM, David. The Media Education Manisfesto. Cambridge: Polity Press, 2019. Edição Kindle.

CAPRINO, Mônica Pegurer; MARTINEZ-CERDÁ, Juan-Francisco. Media Literacy in Brazil: Experiences and Models in Non-formal Education. Media Education Comunicar, [s.l.], n. 49, v. 24, p.39-48, 1 out. 2016. Disponível em: <http://dx.doi.org/10.3916/c49-2016-04〉. Acesso em: 18 jul. 2018.

DESJARDINS, Jeff. What happens in an internet minute in 2019?.Visual Capitalist, 13 mar. 2019. Disponível em: 〈https://bit.ly/2Y0us0L>. Acesso em: 18 ago. 2019. 
FOLHA DE SÃO PAULO. 'Fakenews' alteram hábitos do público, indica pesquisa. São Paulo, 31 out. 2017. Disponível em: <https://goo.gl/UhM8S3>. Acesso em: 18 nov. 2017.

FREIRE, Paulo. Ação cultural para a liberdade. Rio de Janeiro: Paz e Terra, 1978.

FREIRE, Paulo; GUIMARÃES, Sérgio. Educar com a mídia: novos diálogos sobre educação. Paz e Terra: São Paulo, 2013.

GRAGNANI, Juliana. Eleições com fakenews?: Uma semana dentro de 272 grupos políticos no WhatsApp mostra um Brasil dividido e movido a notícias falsas. BBC News, 5 out. 2018. Disponível em: <https://bbc.in/2DuFsdc>. Acesso em 10 out. 2018.

HAN, Byung-Chul. No enxame: perspectivas do digital. Petrópolis: Vozes, 2018. Edição Kindle.

HARARI, Yuval Noah. 21 lições para o século 21. Companhia das Letras, 2018.

Hobbs, R. (2016). When teens create the news: examining the impact of PBS/news hour student reporting labs. Journalism Education, 5(1), pp. 71-73. Disponível em:

<https://goo.gl/f7LHEA>. Acesso em: 10 jul. 2017.

IANDOLI, Rafael. Trump, 'fakenews' e a guerra declarada contra a imprensa. Nexo, 03 jul. 2017. Disponível em: 〈https://goo.gl/sw7Wvq〉. Acesso em: 10 jul. 2017.

LESSENSKI, Marin. Common Sende Wanted: resilience to "post-truth" and its predictors in the news media literacy index 2018. Open Society Institute, mar. 2018. Disponívelem:

<https://bit.ly/33uyfo8>. Acesso em: 25 ago. 2019.

MANJOO, Farhad. True Enough: Learning to live in a post-fat society. John Wiley \& Sons: New Jersey, 2008.

MACKINHTOSH, Eliza. Finland is winning the war on fake news: what it's learned may be crucial to Western democracy. CNN, mai. 2019. Disponível em: 〈https://cnn.it/2svfqnV〉. Acesso em: 12 ago. 2019

MARTHA GABRIEL. (2018). Apresentação. In P. Ferrari (Ed.), Como sair das bolhas. São Paulo: Educ/Armazém da Cultura.

MESSING, Solomon; WESTWOOD, Sean J.. Selective Exposure in the Age of Social Media. Communication Research, [s.1.], n. 8, v. 41, p.1042-1063, 31 dez. 2012. SAGE Publications. Disponível em: <http://dx.doi.org/10.1177/0093650212466406>. Acesso em: 12 out. 2018.

MEC. Base Nacional Curricular Comum. 2017. Disponível em: 〈https://bit.ly/2qNMk2N>. Acesso em: 12 dez. 2018.

MORIN, Edgar. Os sete saberes necessários à educação do futuro. São Paulo: Cortez, 2000; Brasília: UNESCO, 2000.

MORIN, Edgar. Introdução ao pensamento complexo. Porto Alegre: Sulina, 2011. 4 ed.

NATIONAL LITERACY TRUST. Fake News and critical literacy: final report. Disponível em: <https://bit.ly/35MOVIO> Acesso em: 15 jan. 2019.

PEREIRA, Sara e et al. Referencial de Educação para os Media. Direção Geral da Educação, 2014. Disponível em: <https://bit.ly/2OVA8oD>. Acesso em: 12 jul. 2019. 
PINTO, Manuel; PEREIRA, Sara; PEREIRA, Luis; FERREIRA, Tiago Dias. Educação para os media em Portugal: experiências, atores e contextos. Universidade do Minho, 2011. Disponível em: <https://bit.ly/2qWTqBV>. Acesso em: 10 ago. 2019.

RAMONET, Ignacio. A explosão do jornalismo: das mídias de massa à massa de mídia. São Paulo: Publisher Brasil, 2012.

SHOEMAKER, Pamela J. Teoria do gatekeeping: construção e seleção da notícia; tradução: Vivian Nickel. Porto Alegre: Penso, 2011.

TARDÁGLIA, Cristina; BENEVENUTO, Fabricio; ORTELLADO, Pablo. Fake News Is Poisoning Brazilian Politics. WhatsApp Can Stop It. The New York Times, 17 out. 2018. Disponível em: <https://nyti.ms/34yKIbG>. Acesso em: 22 out. 2018.

TUFEKCI, Z. Algorithmic Harms beyond Facebook and Google: Emergent Challenges of Computational. Agency. Colo. Tech. L. J., v.13, 2015. Disponível em: 〈https://bit.ly/37PI6rR〉. Acesso em: 16 jan. 2019.

UNIVERSIDADE DE COIMBRA. Competências de Literacia Digital e Mediática. Coimbra, 2019. Disponível em: 〈https://www.uc.pt/fpce/comedig/Homepage>. Acesso em: 27 set. 2019.

VOSOUGHI, Soroush; DEB, Roy; ARAL, Sinan. The spred of true and false news online. MIT Initiave on the Digital Economy Research Brief, 2018. Disponível em:

<https://bit.ly/33wqqhy>. Acesso em: 19 maio 2018.

WARDLE, Claire; DERAKHSHAN, Hossein. Information Disorder: Toward an interdisciplinary framework for research and policy making. Council of Europe, 2017. Disponível em: <https://bit.ly/37NcPG0>. Acesso em: 22 maio 2018. 